\title{
Research on the Development Trend of Electronic Archives Management in Higher Vocational Colleges
}

\author{
Yang li \\ Personnel Division, Wuxi Vocational Institute of Commerce, Wuxi, 214153, China \\ email: gongwenzi1968@sina.com
}

\begin{abstract}
Keywords: Vocational colleges, Archives management, Electronic documents, Development trends, Impact, Countermeasures
\end{abstract}

\begin{abstract}
The extensive application of electronic documents has had a profound impact on the archives business management of higher vocational colleges from the aspects of paper archives, archival entity classification and custodian duration, and made profound influence on the research contents of archives theory in higher vocational colleges from the aspects of archival nature, archival source principle and archival research content. Vocational college should take countermeasures on the implementation of electronic document management strategy and the solution of electronic file preservation problem in order to promote the archiving management to the three-dimensional, standardized development and the quality of archivist workers. Only in this way, can higher vocational Institutions archives work meet the electronic, information, modernization needs.
\end{abstract}

\section{Introduction}

Electronic records is the new document which is created in the middle of 20th century with the development of computer technology [1]. It is in the form of numbers (bits), through the encoding and decoding to input and output, so it is also known as digital files. It must be computer generated, transmitted and read, and stored on the computer, computer system identification, processing, according to a certain format stored in the disk, CD or mobile hard disk and other media, and can be transmitted on the network [2-3]. It has the characteristics of large storage capacity, fast information transmission and diversification. Compared with paper documents, it has a high degree of sharing, free from time and distance. Electronic documents have become more and more party and government organs, social groups, administrative institutions and individuals widely recognized and applied, it brought the electronic file has become an irresistible trend [4]. It will also have a significant impact on the traditional archives management of higher vocational colleges. Vocational college archives management work should take positive measures in the archives of the electronic context of the file management work to promote the information and modernization [5].

\section{An Analysis of Electronic Archives Theory}

In this paper, the analysis of the electronic archives theory includes the following three parts shown in Fig 1, and the concrete contents are shown as below.

The Comparison with Paperwork. The traditional archival work of higher vocational colleges is based on the paper document material. After the application of computer, the electronic file gradually replaces the previous text material. It is written and modified directly on the disk. Once formed, is will be immediately stored in the office information database, and will be shared by the archives staff and technical staff. This makes the file and the archives no longer have the obvious boundaries. For the management of paper archives after long practice, people have summed up a set of work processes and methods, principles. The filing of documents is the starting point of the archives workflow and the point of integration between paperwork and archival work. In the vocational colleges, there will be a lot of documents and materials in the various departments. After the formation and processing of the documents, the documents shall be collected, rolled up and organized by the part-time archivists of various departments, and then handed over to the 
administration of the archives, which shall be filed once a year. Some of them with independence and special feature need timely filing to keep the original features of documents. Electronic files are readily available, ready to be changed, stored on computer disks or cd-roms, which have a strong dependence on computers and are easily modified. However, it can be in the form of a disk, CD or office automation handover, archive material is original, but the draft and finalized the first-hand materials can also be used by scanning file.

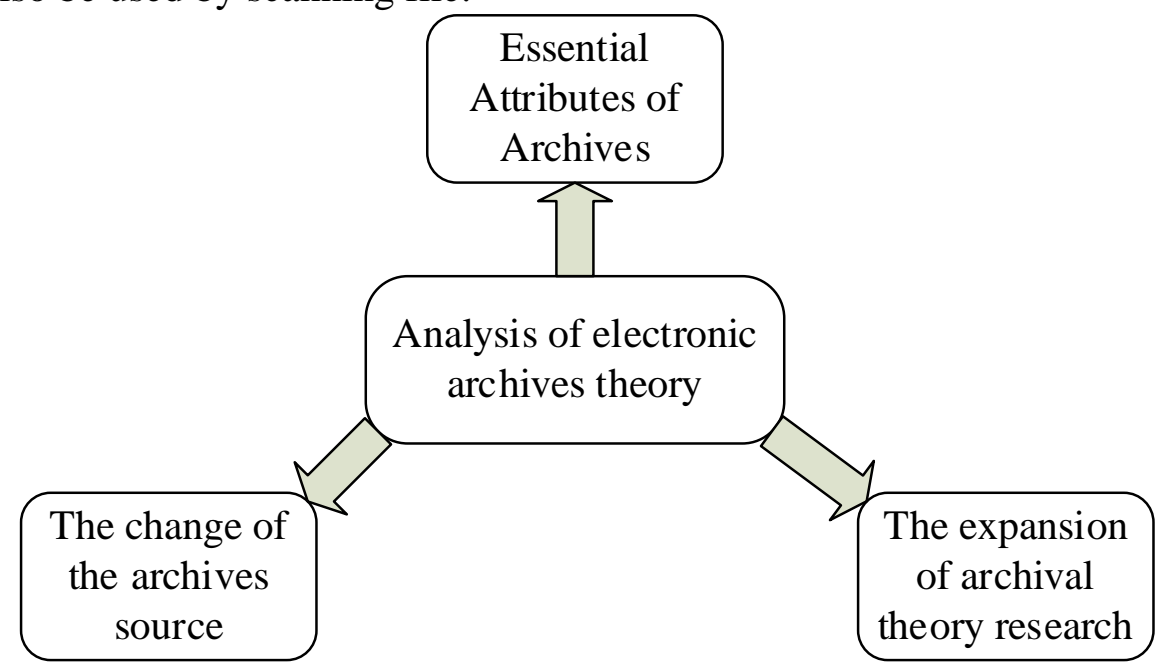

Fig 1. The structure of analysis of the electronic archives theory

The Influences on the Archival Classification. At present, the archives of higher vocational colleges have been developed and implemented in accordance with the actual situation of vocational colleges archives classification method. Due to the particularity of the electronic document information carrier, the classification of archival entities may also be gradually replaced by conceptual sorting. Because the result of entity classification is to embody an attribute link, and this single-line arrangement is the need to manually manage the file, but in today's electronic file environment, the form and feature of the file have changed, and the electronic file can achieve the rapid, effective and multi-angle order through the computer system for, no longer like paper documents as sorting. According to different needs, different users can, use the office automation system to make free combination classification for electronic files.

Analysis of the Custodian Period. As the preservation of electronic documents depends on its own value and readability, so the identification of methods, content, standards will change. The original analysis scope archive value theory will also be expanded, not only to analyze the document itself, but also to analyze the electronic file to read the software or even the operating system. According to the traditional archival value identification theory of higher vocational colleges, the document should be based on its voucher value and reference value to determine the shelf life. In the archives management of vocational colleges, it has long been set the custodian period, and developed a "file storage period table", for a long time. Its archives is to this fixed custody period to save custody. On the one hand, electronic documents can be easily product, saved costs and generated more files. On the other hand, due to the needs of users, the information and data will be constantly modified and added. Thus, it is difficult to delineate a fixed storage period. Moreover, the value of the current voucher of electronic documents need to be further recognized by law. Due to the particularity of the electronic document information carrier, it also has many differences with the paper documents in terms of storage methods, requirements and external use.

\section{Another Analysis of Electronic Archives Theory}

Here, the following three aspects will be discussed, shown in Fig 2. 


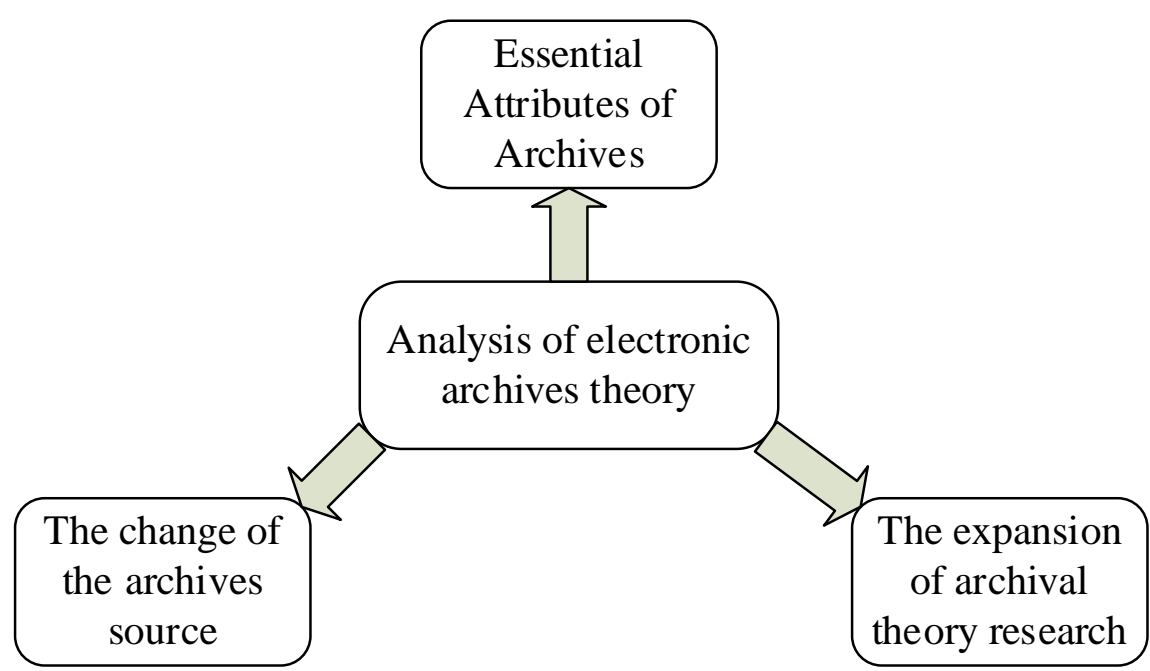

Fig 2. The structure of analysis of electronic archives theory

Essential Attributes of Archives. The original record is the essential attribute of the archives. This original record on the one hand, performs on the contents of the archives, on the other hand, performs on the form of archives. Such as the person's handwritten manuscript, the leader's hand signed, etc., which have shown a true original record. It is also the original record of the archives, which makes the file is different from books, information and other literature, and has the role of legal evidence. In the office automation system, electronic files from the drafting, modification to the release are carried out on the computer. The feature of easy to modify and copy makes the content and form that can reflect the original record no longer exist. The electronic file formed in the file is the last text in the computer word processing system. There is no difference between the draft and the final draft. In addition, there is also no difference between the original and the copy. The file is stored directly in the archives. The electronic file can be copied at any time on the computer. In this way, the file is the predecessor of the archives, and the file conditionally transformed from the file concept becomes blurred. How to determine the authenticity of electronic documents and the role of the certificate, whether the electronic file as a file, whether it has the role of legal evidence, etc., will also be the new issue for our vocational college archives management work to analyze.

The Change of the Archives Source. The principle of archival sources in higher vocational colleges includes two aspects: from the outside point of view, it is the respect for the whole case. From the internal point of view, it is the respect for the original order. At present, with the emergence of a large number of electronic files, the latter is increasingly concerned. The traditional view is that archival retrieval systems based on archival source principles must be based on the organization of documents and information providers and their documents. Only according to its source, from the formation of the legal responsibility and administrative point of view on the problem, can we correctly understand and organize archives. And in the formation process of electronic documents, it is no longer strictly correspond to the existing organization. People can copy and re-combine the document information at any time, which is very easy to disrupt or destroy the original order of the file. Therefore, to determine the source of the file, it is not possible to confine ourselves to find an exact definition, or only to complete the protection of the whole series and the document series, sort in the original order, etc.

The Expansion of Archival Theory Research. The contents of the study of archival theory are determined by the research object. In the past, the study of archival science has taken the paper as the main object. After the emergence of electronic documents, the object of archives work in higher vocational colleges has changed, and the object of theoretical research has changed. Some of the original conclusion and model will be re-examined, the original management ideas and management principles will be updated and added, the original archives discipline system will be enriched and improved. All of these research topics should be carried out around electronic documents. Such as electronic file sorting technology, information security protection technology, 
computer virus prevention technology, etc., will become an indispensable content of archival theory research.

\section{The Discussion on Electronic Archives Management in Higher Vocational Colleges}

The following four parts will be stated in this section, shown in Fig 3.

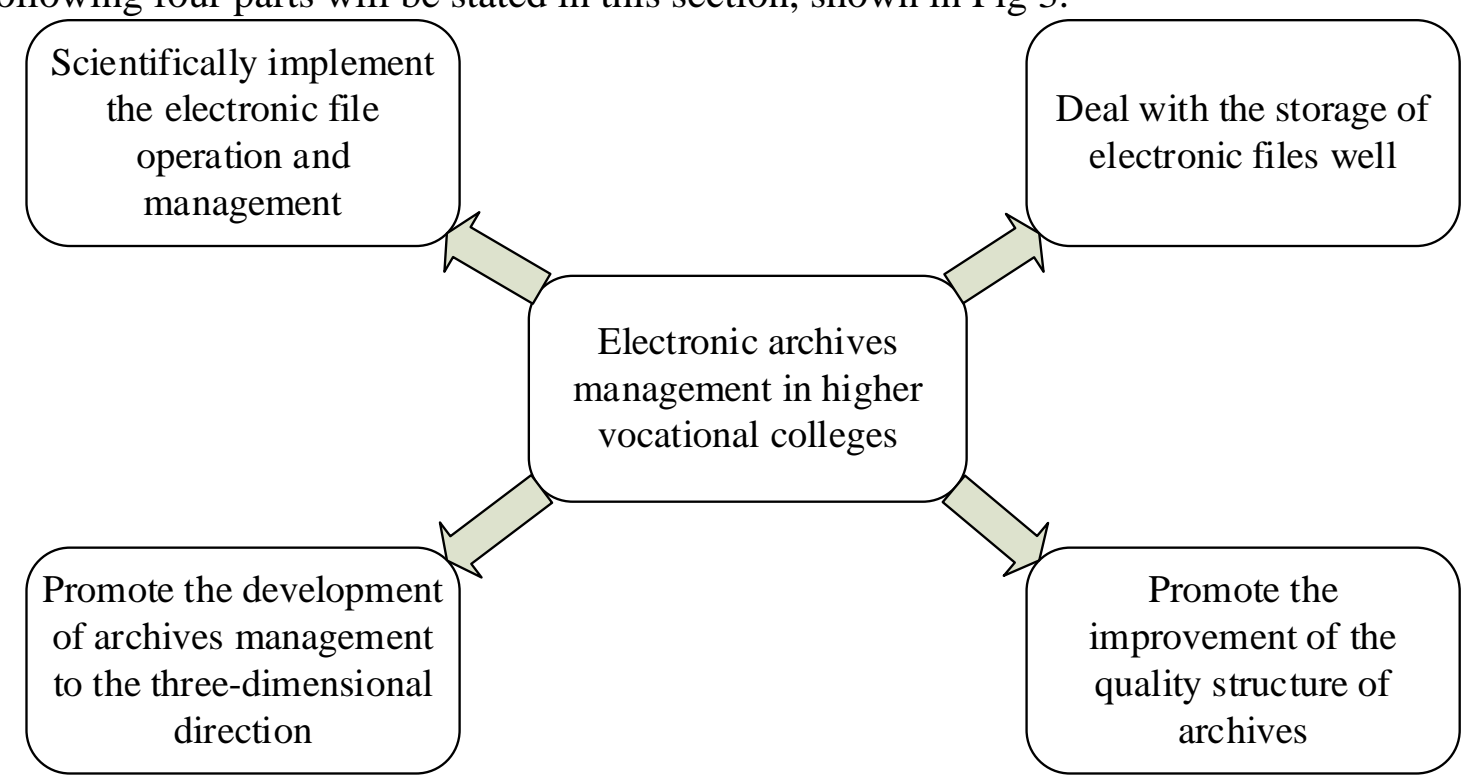

Fig 3. The structure of electronic archives management

Scientifically Implement the Electronic File Operation and Management. It is imperative to file the electronic document material in higher vocational colleges. This requires archivists to go deep into the current work area of the document, guide the receiving, handling and storing work of a large number of electronic documents. For the electronic files, electronic archives and electronic computer hardware and software technology and related equipment, there is a close relationship among them. And in the electronic file archiving, we must understand the formation of electronic files corresponding software and equipment. In the electronic document design formation stage, archivists will participate in the design, guidance, so that the resulting electronic files can be archived according to the requirements, and can be unified management and long-term preservation. At the same time, it is necessary to understand the background, design intent, data form, and the corresponding computer hardware and software technology of long-term preservation of the electronic file. After the formation of electronic documents, in the usage process, the archivists have to follow the monitoring, the failure of the timely processing. In terms of management, electronic files are an important form of electronic files. Therefore, the authors of electronic documents and the administrator of electronic archives should work together to ensure the accessibility, readability, and understandability of electronic files. Therefore, in the era of electronic documents, the management of document integration is imperative.

Deal with the Storage of Electronic Files Well. Electronic documents gradually become the main electronic file. Vocational college archives on the relevant electronic file storage and preservation has an inescapable historical responsibility. The magnetic material as the carrier of the electronic file, in theory, can be long-term preservation, because its information read is non-contact, and there is no wear. Electronic documents recorded in the media layer of information is sealed in the plastic protective layer, not afraid of the impact of external magnetic field, not directly by the air in the dust, moisture and harmful gases. However, due to the short time of electronic file formation and lack of verification of actual storage, the long-term preservation of original information in electronic documents is an important subject for further study and discussion of archives workers in vocational colleges. At present, for long-term preservation of electronic documents, in addition to the general requirements, it also should be modified to do the archive carrier, and the carrier should be stored upright, kept away from the strong magnetic field. Moreover, it also need to be regularly 
checked, copied to prevent damage and loss of information.

Promote the Development of Archives Management to the Three-dimensional Direction. The archive management of higher vocational colleges in the past presents the straight line shape. With the majority of faculty and staff of vocational colleges on the importance of file inquiries, archive query work and other basic work form a plane, but this plane structure only reflects the paper file situation. With the involvement of electronic documents, file types are increasing, the basic work and query work also have their own personality. Therefore, on the basis of the original plane structure, and added a file information carrier content, which constitutes a three-dimensional management structure.

Promote the Improvement of the Quality Structure of Archives. The profound changes of archives work urgently need archives managers to adapt to their own qualities, which requires vocational colleges to forge a high-quality composite file management personnel to adapt to the information age of vocational colleges need. It can be said that the archives manager's own knowledge, skills and other elements of quality structure have become a vocational college archives electronic work, information technology, the basis of modernization and the key. It requires archives professionals must become the compound talents engaged in modern secret documents, books, information and other comprehensive information management. Thus, this requires the archives management personnel in higher vocational colleges not only to master the basic theory and basic knowledge of the professional, with strong file management capabilities, master the file management procedures, but also master the use of computer hardware and software technology. Vocational colleges should be self-taught and planned, phased training and re-education, the existing staff of knowledge updates, broaden their business knowledge, so that they can keep up with the pace of high-tech development to meet the higher vocational institutions archives work electronic, information, modernization needs.

\section{Conclusion}

The extensive application of electronic documents has had a profound impact on the archives business management of higher vocational colleges from the aspects of paper archives, archival entity classification and custodian duration. This paper analyzes the current situation of the management of electronic archives in vocational colleges from the comparison of the paperwork, the impact of archival entity classification and the analysis of storage period. Then, it analyzes the theory of electronic archives, including the essential attributes of archives, the change of archival source principle and the expansion of archival theory research contents. Finally, the management mode of electronic archives in higher vocational colleges is discussed, with a view to providing guidance and reference for the future development of electronic archives management mode in higher vocational colleges.

\section{References}

[1] Ma Xuehua. Discussion on the management development of electronic archives in higher vocational college[J]. Journal of Yellow River Conservancy Technical Institute, 2008, 20(1): 83-85.

[2] Yao Xiaoju. Analysis of electronic archives management in higher vocational colleges[J]. Journal of Jiamusi Vocation Institue, 2015, 2: 320-322.

[3] Song Lingya. My view on teaching e-file management[J]. Journal of Nanjing Institue of Industry Technology, 2006, 6(3): 53-54.

[4] Zhang Yanyan. On how to do scientific research archives management well in vocational colleges[J]. Journal of Baotou Vocational and Technical College, 2015, 16(4): 94-96.

[5] Dai Tingting. Research on electronic documents and their archives management in higher vocational colleges[J]. Journal of Kuohe Vocational Technology College, 2015, 14(6): 191-192. 